\title{
Pentalogy of Cantrell: case report
}

\author{
Col Yoginder Singh*, Sqn Ldr Navneet Magon+, Brig S Chopra, VSM\#, Brig SK Kathpalia**
}

MJAFI 2011;67:291-292

\section{INTRODUCTION}

Pentalogy of Cantrell (thoracoabdominal ectopia cordis) is a rare congenital syndrome of abdominal wall defect, lower sternal defect, diaphragmatic pericardial defect, anterior diaphragmatic defect, and intracardiac abnormalities. First described by Cantrell in 1958, the syndrome occurs sporadically with variable degrees of expression. ${ }^{1}$ Less than 90 cases have been reported in the literature. The defect is characterized by the association of five anomalies, viz. omphalocoele, cardiac ectopia, absence of the distal portion of the sternum, absence of the anterior diaphragm, and absence of the parietal pericardium. It has a rare frequency of about $1 / 100,000$ births. $^{2}$ The proposed pathogenesis involves a defect in embryogenesis between 14 and 18 days after conception, when the splanchnic and somatic mesoderm is dividing. Chromosomal abnormalities have also been associated with the syndrome prenatal diagnosis by ultrasonography is possible, depending on the size and extent of the defects. We report a case of pentalogy of Cantrell diagnosed in early second trimester.

\section{CASE REPORT}

A 23-years-old primigravida at 16 weeks 2 days gestational age reported to our antenatal OPD. The patient denied significant medical problems, as well as any known history of cardiac or other congenital anomalies in her family. She reported taking no medications except folic acid, iron, and calcium supplements. There was no family history of diabetes and her blood sugar was normal. On taking detailed history, she revealed that she had a consanguineous marriage with her mother's brother (autosomal disorders are more common in consanguineous marriages, although the mode of inheritance of this syndrome is not known). On examination, her general and abdominal examination did not reveal any significant finding and uterine height was corresponding to the period of gestation. Ultrasound done at our foetal medicine centre revealed absent sternum, ectopia cordis, absent

\footnotetext{
*Associate Professor, Fetal Medicine, **Prof and Head, Department of Obst and Gynae, AFMC, Pune, ${ }^{\# B r i g}$ (Training), AFMC, ${ }^{+}$Graded Specialist (Obst and Gynae), 7 AF Hospital, C/O 56 APO.
}

Correspondence: Col Yoginder Singh, Associate Professor, Fetal Medicine, Department of Obstetrics and Gynecology, AFMC, Pune - 40. E-mail:yogiranal1@gmail.com

Received: 06.02.2010; Accepted: 20.02.2011

doi: $10.1016 /$ S0377-1237(11)60065-8 diaphragm, and omphalocoele (Figure 1). Amniocentesis was done which showed normal karyotype. The maternal serological tests to toxoplasmosis, rubella, and cytomegalovirus were negative. In view of incompatibility with normal life she was offered termination of pregnancy, which she opted for. Foetal autopsy revealed omphalocoele, cardiac ectopia, absence of the distal portion of the sternum, absence of the anterior diaphragm, and absence of the parietal pericardium (Figure 2). A foetogram was done (Figure 3 ) revealing bow legs and a short umbilical cord.

\section{DISCUSSION}

The sternum, abdominal wall, pericardium, and part of the diaphragm arise from somatic mesoderm, while the myocardium arises from splanchnic mesoderm. An event occurring prior to differentiation of the mesoderm into these two layers could produce defects in all of the involved structures, as seen in pentalogy of Cantrell. Although a specific aetiology is unknown, the timing of the event or insult would be between 14 and 18 days after conception. The proposed embryogenesis postulates a failure of the lateral mesodermal folds to migrate to the midline, causing the sternal and abdominal defects, and failure of the septum transversum to develop, causing defects in the anterior diaphragm and pericardium.

Diagnosis of the complete syndrome requires the five criteria described by Cantrell, but incomplete variant forms exhibiting three or four of the features have been described. The sternal

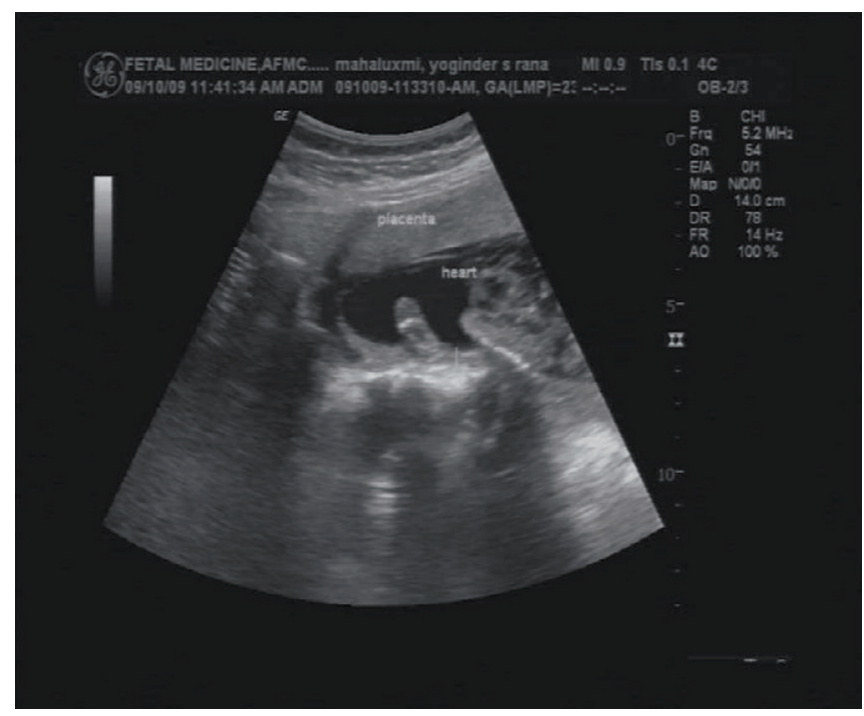

Figure 1 Ultrasonography of foetus showing ectopia cordis. 


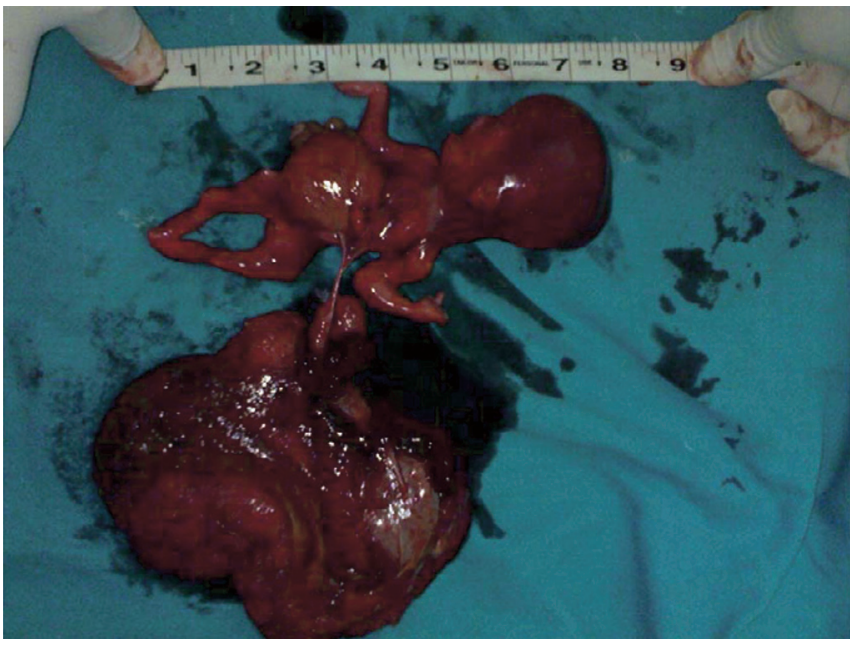

Figure 2 Gross specimen of foetus.

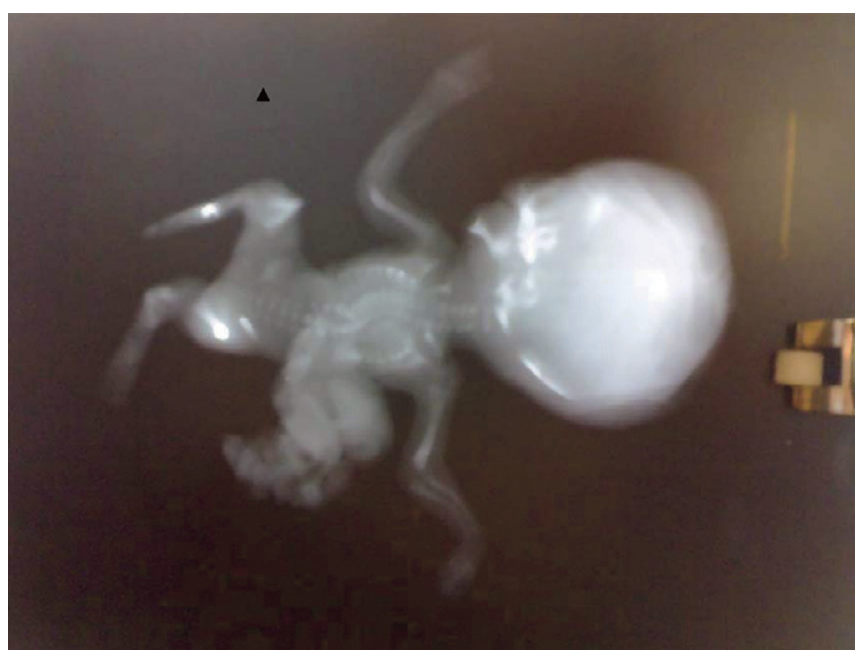

Figure 3 Foetogram of abortus.

defect can range from absence of the xiphoid to cleaving, shortening, or absence of the entire sternum. The abdominal defect can range from a wide rectus muscle diastasis to a large omphalocoele. $^{3}$ The most common intracardiac defects are atrial septal defect, ventricular septal defect, and tetralogy of Fallot. The syndrome has been diagnosed prenatally, but as the defects range from subtle to severe; the ability to make the ultrasound diagnosis varies. Even at birth, the full extent of the syndrome may not be apparent, as the sternal defect may be minor and therefore without true ectopia cordis. ${ }^{3}$ In our case ectopia cordis was present and sternum was absent. In 1972, Toyama reported a survival rate of $20 \%{ }^{4}$ This included cases with mild defects and incomplete expressions of the syndrome, and all cases were diagnosed post-partum.

In 1988, Ghidini reported upon 17 prenatally diagnosed cases; six patients opted for termination, four infants were stillborn, four infants died in the first four days after delivery, and the remaining three died at first, fourth, and fifth months, respectively. ${ }^{5}$ This gave a survival rate of $0 \%$. These cases were prenatally diagnosed, so the extent of anomalies could have been more severe than those cases detected at birth. Three of the five patients Cantrell reported in 1958 survived, but none of the five had true ectopia cordis. Overall the prognosis appears dismal, but may be related to the extent of the defects. Differential diagnosis includes isolated ectopia cordis, isolated abdominal wall defect, amniotic band syndrome, and body stalk anomaly. The syndrome should be considered with any diagnosis of omphalocoele or ectopia cordis. Recurrence risk is not known.

If a diagnosis is made by ultrasound, then chromosomal analysis is recommended. ${ }^{6}$ Associations with trisomy 18 , trisomy 13, and Turner syndrome have been reported. Careful imaging should be performed to rule out associated anomalies. Foetal echocardiography is indicated to evaluate the extent of any intracardiac abnormalities. Foetal MRI may be useful in selected cases. ${ }^{7}$ In view of the poor prognosis, termination of pregnancy may be considered if ultrasound diagnosis is made before viability. In patients choosing to continue the pregnancy, there is no data indicating improved or changed outcome with caesarean delivery. After delivery, repair of the omphalocoele should not be delayed. Repair of the sternal, diaphragmatic, and pericardial defects can be attempted at the same time. Surgical correction is often difficult secondary to hypoplasia of the thoracic cage and inability to enclose the ectopic heart. Some affected infants have respiratory insufficiency secondary to pulmonary hypoplasia. Recognition and treatment of any intracardiac anomaly is important, as congenital heart disease is a source of major morbidity in infants surviving the neonatal period. Alagappan described a similar case report in $2005 .{ }^{8}$ Case report is submitted for two reasons: one is that it is a very rare syndrome and the other is to further highlight the importance of performing second trimester anomaly scans.

\section{REFERENCES}

1. Cantrell JR, Haller JA, Ravitch MM. A syndrome of congenital defects involving the abdominal wall, sternum, diaphragm, pericardium, and heart. Surg Gynecol Obstet 1958;107:602-614.

2. McMahon CJ, Taylor MD, Cassady Cl, Olutoye 00, Bezold LI. Diagnosis of pentalogy of Cantrell in the fetus using magnetic resonance imaging and ultrasound. Pediatr Cardiol 2007;28:172-175.

3. Grethel EJ, Hornberger LK, Farmer DL. Prenatal and postnatal management of a patient with pentalogy of Cantrell and left ventricular aneurysm. Fetal Diagn Ther 2007;22:269-273.

4. Toyama WM. Combined congenital defects of the anterior abdominal wall, sternum, diaphragm, pericardium, and heart: a case report and review of the syndrome. Pediatrics 1972;50:778-792.

5. Ghidini A, Sirtori M, Romero R, Hobbins JC. Prenatal diagnosis of pentalogy of Cantrell. J Ultrasound Med 1988;7:567-572.

6. Bittmann S, Ulus H, Springer A. Combined pentalogy of Cantrell with tetralogy of Fallot, gallbladder agenesis, and polysplenia: a case report. J Pediatr Surg 2004;39:107-109.

7. Oka T, Shiraishi I, Iwasaki N, Itoi T, Hamacka K. Usefulness of helical $\mathrm{CT}$ angiography and MRI in the diagnosis and treatment of pentalogy of Cantrell. J Pediatr 2003;142:84.

8. Alagappan P, Chellathurai A, Swaminathan TS, Mudali S, Kulasekaran N. Pentalogy of Cantrell. Indian J Radiol Imaging 2005;15:81-84. 